intra-atrial septum. This further required effective excision of the infected tissue. The interatrial septum was patched with bovine pericardium and the roof of the left atrium and the posterior wall of the aorta. The prosthetic valve replacement still remains the standard surgical approach despite the reported success with homografts, autografts, and xenografts. ${ }^{5}$

\section{CONCLUSIONS}

We report a rare case of aortic valve endocarditis caused by $L$ jensenii after a normal vaginal delivery in a patient with bicuspid aortic valve, which was complicated by severe aortic regurgitation and extensive aortic root abscess that further required a complex surgery.

\section{References}

1. Gasser F. Safety of lactic-acid bacteria and their occurrence in human clinical infections. Bull Inst Pasteur. 1994;92:45-67.

2. Brougui P, Raoult D. Endocarditis due to rare and fastidious bacteria Clin Microbiol Rev. 2001;14:177-207.

3. Knosalla C, Weng Y, Yankah AC, Siniawski H, Hofmeister J, Hammerschmidt R, et al. Surgical treatment of active infective aortic valve endocarditis with associated periannular abscess -11 year results. Eur Heart J. 2000;21:490-7.

4. Okada K, Okita Y. Surgical treatment for aortic periannular abscess/pseudoaneurysm caused by infective endocarditis. Gen Thorac Cardiovasc Surg. 2013;61:175-81.

5. Armani M, Schoevardts JC, Eucher P, Niicolas AL, Dion R, Kremer R. Extension of native aortic valve endocarditis: surgical considerations. Eur Heart J. 1995; 16(Suppl B):103-6.

\title{
Successful surgical treatment of rare Aspergillus terreus prosthetic valve endocarditis complicated by intracranial and mesenteric artery mycotic aneurysms
}

\author{
Rania A. R. Ahmad, MD, ${ }^{a}$ Syed T. Hussain, MD, ${ }^{b}$ Carmela D. Tan, MD, ${ }^{c}$ Gösta B. Pettersson, MD, PhD, ${ }^{b}$ \\ Daniel Clair, MD, ${ }^{\mathrm{d}}$ and Steven M. Gordon, MD, ${ }^{\mathrm{a}}$ Cleveland, Ohio
}

Aspergillus endocarditis (AE) is a rare and ominous cause of infective endocarditis. ${ }^{1-3} \mathrm{AE}$ is often disseminated and fatal, and detection of its source, establishment of the diagnosis, and treatment are highly challenging. We report an advanced case of prosthetic valve endocarditis caused by the species Aspergillus terreus, complicated by intracranial and superior mesenteric artery mycotic aneurysms, recent intracranial bleeding, and multiple peripheral embolic episodes.

\section{CLINICAL SUMMARY}

A 39-year-old man with a severely stenotic bicuspid aortic valve underwent mechanical aortic valve replacement in May 2013, complicated by complete heart block

\footnotetext{
From the Department of Infectious Disease, ${ }^{a}$ Medicine Institute; the Departments of Thoracic and Cardiovascular Surgery ${ }^{\mathrm{b}}$ and Vascular Surgery, ${ }^{\mathrm{d}}$ Heart and Vascular Institute; and the Department of Anatomic Pathology, ${ }^{\mathrm{c}}$ Laboratory Medicine Institute, Cleveland Clinic, Cleveland, Ohio.

R.A.R.A. is currently at Sheikh Khalifa Medical City, Abu Dhabi, United Arab Emirates. Disclosures: Authors have nothing to disclose with regard to commercial support.

Received for publication June 4, 2014; accepted for publication June 5, 2014; available ahead of print Aug 23, 2014.

Address for reprints: Gösta B. Pettersson, MD, PhD, Department of Thoracic and Cardiovascular Surgery, Cleveland Clinic, 9500 Euclid Ave, Desk J4-1, Cleveland, OH 44195 (E-mail: petterg@ccf.org).

J Thorac Cardiovasc Surg 2014;148:e221-3

$0022-5223 / \$ 36.00$

Copyright (C) 2014 by The American Association for Thoracic Surgery

http://dx.doi.org/10.1016/j.jtcvs.2014.06.084
}

requiring permanent pacemaker implantation. Four months later, he presented with lower extremity embolus requiring embolectomy. The removed embolus grew Aspergillus, not further speciated. Echocardiography showed vegetations at the sinotubular junction and in the aortic root, and the patient underwent reoperation with removal of infectious vegetations and augmentation of the aorta with bovine pericardial patch, without replacement of the valve prosthesis. The vegetations grew Aspergillus species. During treatment with amphotericin B and voriconazole, the patient had developed an abscess in the left lower forearm requiring surgical drainage. The culture grew Aspergillus, prompting transfer to our institution in February 2014.

Within 24 hours of arrival, the patient had acute embolic occlusion of the right superficial femoral and profunda femoris arteries requiring urgent thromboembolectomy. The embolus grew A terreus, speciated for the first time, and the antifungal treatment was changed from amphotericin $B$ to voriconazole and micafungin sodium (INN micafungin) on the basis of sensitivity. Echocardiography showed large, mobile vegetations in the proximal aorta near the sinotubular junction (Figure 1, A). Computed tomographic scan of the abdomen revealed a 6-cm superior mesenteric artery aneurysm with surrounding inflammation (Figure 1, $B)$. Head computed tomography showed multiple small 

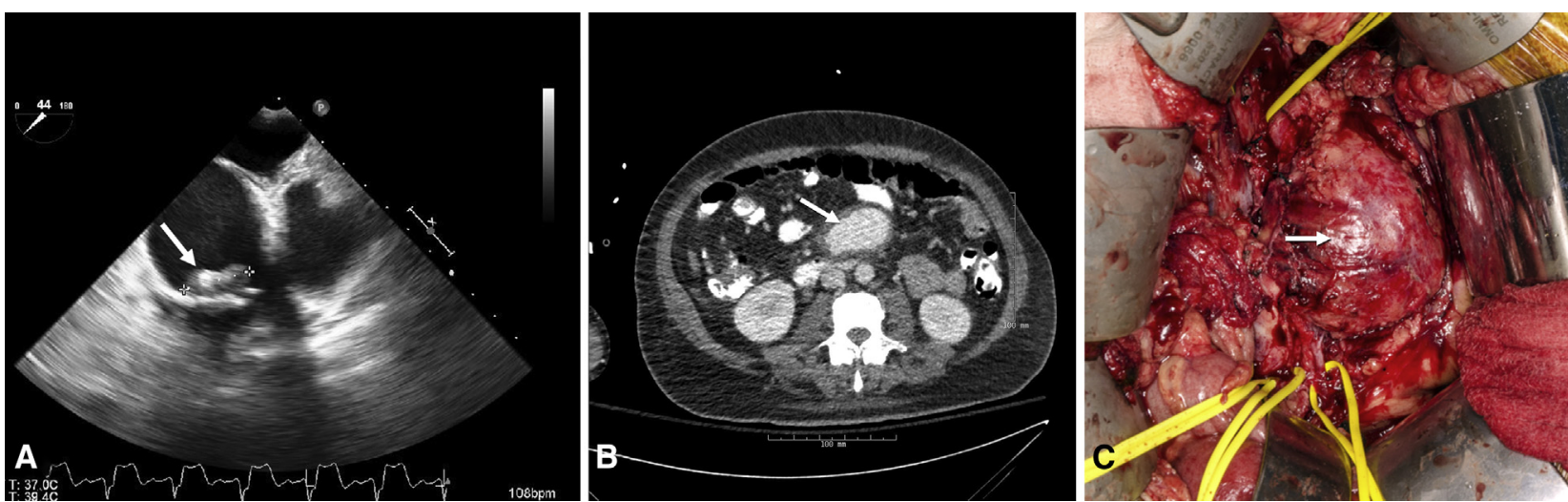

FIGURE 1. A, Echocardiogram showing large vegetations in proximal aorta (arrow) near sinotubular junction. B and C, Large saccular aneurysm of superior mesenteric artery (arrow) on computed tomography (B) and intraoperative view (C).

hemorrhages, and cerebral angiography revealed a small mycotic aneurysm that was treated by endovascular coil embolization. To prevent further embolic events, the patient was urgently taken for a third cardiac reoperation. Intraoperatively, large vegetations were found mainly over the bovine pericardial patch used during the previous vegetectomy, and the surrounding periaortic tissue was inflamed and possibly infected. Radical aortic root débridement, allograft aortic root replacement, and complete removal of the pacemaker and leads were performed. Four days later, the superior mesenteric artery saccular aneurysm was repaired by direct surgical closure of the neck (Figure 1,C). The following week, a new permanent pacemaker was implanted. The remainder of the postoperative course was uneventful. All specimens grew A terreus (Figure 2). The patient received 6 weeks of micafungin and is scheduled for lifelong voriconazole as secondary prophylaxis. He is doing well at home at 2-month follow-up.
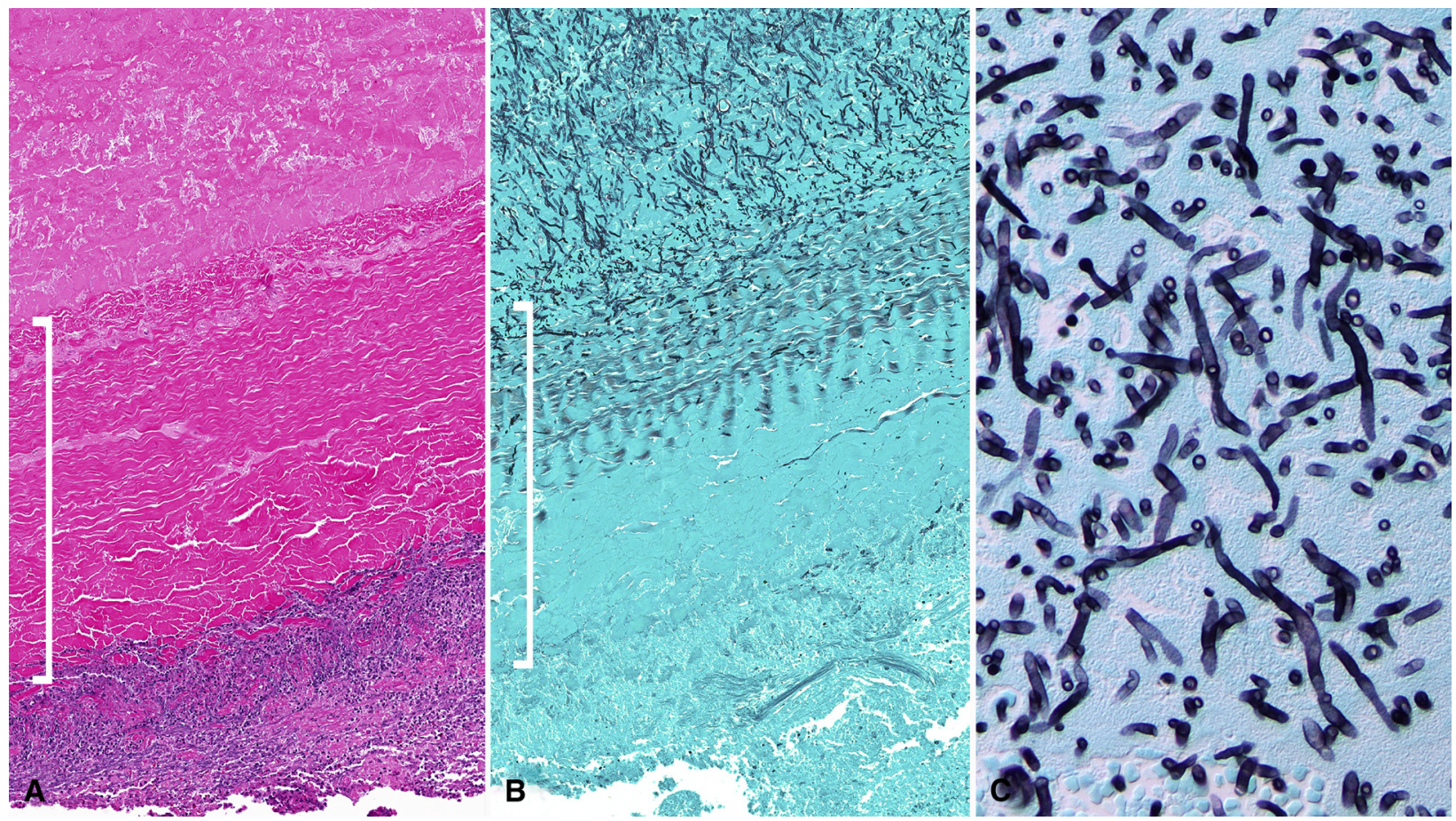

FIGURE 2. The pericardial patch, composed of dense wavy collagen bundles, is marked by a white bracket (A, B). On top of the patch is a vegetation (C) containing branching septated fungal hyphal forms that invade into the superficial portion of the patch. Acute inflammatory infiltrates forming abscesses are present underneath the patch. A, Hematoxylin-eosin, 200× original magnification; B, Gomori methenamine silver, $200 \times$ original magnification; C, Gomori methenamine silver, $400 \times$ original magnification. 


\section{DISCUSSION}

Aspergillus is a rare cause of endocarditis. ${ }^{1-3}$ The prognosis for $\mathrm{AE}$ is poor, with only a third of reported patients surviving the acute episode, in part because of immunocompromise, delay in diagnosis, systemic dissemination, and multiple embolic episodes. ${ }^{1}$ Only 5 cases of infective endocarditis caused by the species A terreus have been reported. ${ }^{1}$ To the best of our knowledge, this is the first reported case of prosthetic valve endocarditis caused by $A$ terreus.

Early and accurate diagnosis is the most critical step in the treatment of $\mathrm{AE}$ and requires a high index of suspicion. The occurrence of peripheral emboli is the most common presenting feature and in a culture-negative infective endocarditis setting should raise the suspicion of $\mathrm{AE} .{ }^{1,3,4}$ Echocardiography reveals large vegetations on the valve(s), but blood cultures are almost always negative..$^{1-3}$ Ultimately, the diagnosis of Aspergillus requires histology and tissue culture confirmation from vegetations or emboli. Determining species is critical, because A terreus species is almost always resistant to amphotericin $\mathrm{B}$, and voriconazole is the antifungal drug of choice, often in combination with an echinocandin. ${ }^{1}$

Mortality is extremely high among those who receive antifungal therapy alone. ${ }^{1-3}$ Successful treatment of $\mathrm{AE}$ requires combination of appropriate antifungal therapy and radical surgical debridement. Despite adequate combined antifungal and radical surgical treatment, recurrence after $\mathrm{AE}$ as high as $40 \%$ has been reported, adding to the dismal prognosis. ${ }^{1-3}$ As a consequence, we now recommend antifungal suppression for life.
Our patient was not immunosuppressed. El-Hamamsy and colleagues reported a cluster of 3 immunocompetent cases of $\mathrm{AE}$ after aortic valve replacement in which the source could not be identified. ${ }^{5}$ They suggested seeding by airborne spores as probable cause, emphasizing importance of operating room sterility and use of highefficiency particulate air filters.

In conclusion, $\mathrm{AE}$ is a rare, often fatal infection requiring a high index of suspicion, multidisciplinary team approach for expeditious and accurate diagnosis, and appropriate antifungal and surgical treatment. Diagnosis requires histology and culture. Species diagnosis of AE is critical, because A terreus is resistant to amphotericin B. Immediate surgical intervention with radical debridement and lifelong antifungal therapy remains the best hope of improved prognosis.

\section{References}

1. Kalokhe AS, Rouphael N, El Chami MF, Workowski KA, Ganesh G, Jacob JT Aspergillus endocarditis: a review of the literature. Int J Infect Dis. 2010;14 e1040-7.

2. Gumbo T, Taege AJ, Mahorter S, McHenry MC, Lytle BW, Cosgrove DM, et al. Aspergillus valve endocarditis in patients without prior cardiac surgery. Medicine (Baltimore). 2000;79:261-8.

3. El-Hamamsy I, Dürrleman N, Stevens LM, Perrault LP, Carrier M Aspergillus endocarditis after cardiac surgery. Ann Thorac Surg. 2005; 80:359-64.

4. Ryu KM, Seo PW, Kim SH, Park S, Ryu JW. Surgical treatment of native valve Aspergillus endocarditis and fungemic vascular complications. J Korean Med Sci. 2009;24:170-2.

5. El-Hamamsy I, Dürrleman N, Stevens LM, Cartier R, Pellerin M, Perrault LP, et al A cluster of cases of Aspergillus endocarditis after cardiac surgery. Ann Thorac Surg. 2004;77:2184-6.

\title{
Familial Ebstein's anomaly, left ventricular noncompaction, and ventricular septal defect associated with an $\mathrm{MYH7}$ mutation
}

\author{
Keiichi Hirono, MD, ${ }^{a}$ Yukiko Hata, PhD, ${ }^{b}$ Keijirou Ibuki, MD, ${ }^{a}$ and Naoki Yoshimura, MD, ${ }^{\mathrm{c}}$ Toyama, Japan
}

Left ventricular noncompaction (LVNC) is a rare cardiomyopathy characterized by prominent trabeculations with deep intertrabecular recesses. ${ }^{1}$ Ebstein's anomaly is a rare congenital heart defect, and familial cases are

\footnotetext{
From the Departments of Pediatrics, ${ }^{\mathrm{a}}$ Legal Medicine, ${ }^{\mathrm{b}}$ and 1st Surgery, ${ }^{\mathrm{c}}$ Graduate School of Medicine, University of Toyama, Toyama, Japan.

Disclosures: Authors have nothing to disclose with regard to commercial support. Received for publication Aug 11, 2014; accepted for publication Aug 20, 2014.

Address for reprints: Keiichi Hirono, MD, Department of Pediatrics, Graduate School of Medicine, University of Toyama, 2630 Sugitani, Toyama City, Toyama, 9300194 Japan (E-mail: khirono1973@gmail.com).

J Thorac Cardiovasc Surg 2014;148:e223-6

$0022-5223 / \$ 36.00$

Copyright (c) 2014 by The American Association for Thoracic Surgery

http://dx.doi.org/10.1016/j.jtcvs.2014.08.049
}

uncommon. ${ }^{2,3}$ These genetic causes have not been fully elucidated.

We describe clinical and molecular investigations of a rare case of familial Ebstein's anomaly, LVNC, and ventricular septal defect (VSD) in association with a likely pathogenic novel mutation of the MYH7 (c.1085T $>$ G, p.Met362Arg) gene. The sister and brother have been diagnosed with $\mathrm{Eb}$ stein's anomaly, LVNC, and VSD, and novel mutation was identified in the sister, brother, and father.

\section{CLINICAL SUMMARY}

Case 1 (the Proband)

The patient was a full-term infant with a birth weight of $3.42 \mathrm{~kg}$ and Apgar scores of 9 and 10 at 1 and 5 